\title{
Avaliação dos egressos de engenharias: um estudo a partir da inserção e desafios no mercado das primeiras turmas da UFSJ (2013-2017)
}

\author{
Evaluation of graduates of engineering: A study from the insertion and \\ challenges in the market of the first classes of the UFSJ (2013-2017)
}

\begin{abstract}
Daniel Calbino ${ }^{1}$ - Universidade Federal de São João del Rei | São João del Rei | MG | Brasil. Contato: dcalbino@ufsj.edu.br. ORCID: http://orcid.org/0000-0001-8260-6126
\end{abstract}

Priscila da Silva Castro - Universidade Federal de São João del Rei | São João del Rei | MG | Brasil. Contato: priscilacastro891@gmail.com. ORCID: http://orcid.org/0000-0003-1978-8830

Edinalva Rodrigues Gonçalves ${ }^{3}$ - Universidade Federal do Vale do Jequitinhonha e Mucuri | Programa de Mestrado em Educação | Teófilo Otoni | MG | Brasil. Contato: edinalvargoncalves@ gmail.com. ORCID: https://orcid.org/0000-0002-8662-8194

Geruza Tomé Sabino ${ }^{4}$ - Universidade Federal do Vale do Jequitinhonha e Mucuri| Programa de Mestrado em Educação | Teófilo Otoni | MG | Brasil. Contato: geruzaft@ hotmail.com. ORCID: http://orcid.org/0000-0002-2247-0869

Resumo: O trabalho teve como objetivo avaliar os egressos das Engenharias, tendo por recorte os ex-alunos das primeiras turmas da Universidade Federal de São João del Rei-MG. Enquanto percurso metodológico recorreu-se a análise estatística descritiva do perfil sociocultural e desempenho acadêmico de todas as matrículas do Campus. Em seguida foram realizadas entrevistas em forma de questionário online com os egressos. Os resultados indicam que os egressos constituem apenas $23 \%$ dos alunos que colaram grau, cujo perfil é feminino (69,0\%), solteiro (86,5\%) e oriundo do estado de Minas Gerais $(93,5 \%)$. Referente aos desafios da inserção no mercado de trabalho, observou-se que o índice de rejeição nos processos seletivos nas pós-graduações foram baixos $(9,2 \%)$ em comparação com as tentativas de trabalho nas iniciativas privadas $(48,9 \%)$, o que parece ilustrar a atual crise econômica do país. Por fim, as avaliações em relação à instituição de ensino cursada foram positivas na percepção dos egressos, sendo que para a maioria dos que não estão atuando $(62,5 \%)$, atribuiu-se a falta de oportunidades no mercado. Em vista do alto índice de desocupados, os dados da pesquisa se mostram relevantes para a criação de indicadores de avaliação dos cursos e da própria gestão Universitária, bem como, refletir sobre os desafios da formação do ensino superior em engenharia na empregabilidade do século XXI.

Palavras-chave: Egresso. Mapeamento do perfil. Mercado de trabalho. Avaliação institucional.

Abstract: The objective of this study was to evaluate the egress of Engineering, with a cut-off of the alumni of the first groups of the Federal University of São João del Rei-MG. As a methodological course we used the descriptive statistical analysis of the sociocultural profile and academic performance of all the enrollments of the Campus. Then, interviews were conducted in the form of an online questionnaire with the graduates. The results indicate that graduates make up only $23 \%$ of the students who enrolled in a degree, whose profile is female $(69.0 \%)$, single (86.5\%) and from the state of Minas Gerais $(93.5 \%)$. Regarding the challenges of insertion in the labor market, it was observed that the rejection rate in the postgraduate selective processes were low (9.2\%) compared to the attempts to work in private initiatives (48.9\%), which seems to illustrate the current economic crisis of the country. Finally, the evaluations in relation to the institution of education were positive in the perception of the graduates, and for the majority of those who are not working $(62.5 \%)$, the lack of opportunities in the market was attributed. In view of the high unemployment rate, the research data are relevant for the creation of indicators for the evaluation of the courses and for the University management itself, as well as to reflect on the challenges of engineering higher education in 21 st century employability.

Keywords: Egress. Mapping profile. Job market. Institutional evaluation.

- Recebido em: 6 de setembro de 2018 • Aprovado em: 30 de maio de 2020

DOI: http://dx.doi.org/10.1590/S1414-40772020000200013

Este é um artigo publicado em acesso aberto sob uma licença Creative Commons

https://creativecommons.org/licenses/by-nc/4.0/ 


\section{Introdução}

Pesquisas com egressos são realizadas desde a década de 1930, nos Estados Unidos, relacionados a opinião sobre satisfação no trabalho, relação entre as universidades e o mercado de trabalho (TEIXEIRA et al., 2014). Além do pioneirismo nas pesquisas, destacam-se ações contínuas para a manutenção do relacionamento com seus egressos, fundamentais, também, para captação de recursos.

Coelho e Oliveira (2012) ressaltam que em países da União Europeia a realização de pesquisas com egresso é prática cotidiana, com vistas, especialmente, a avaliar o ensino ofertado, realizar modificações ou ajustes nos conteúdos curriculares e articulações com outros setores, sobretudo o de emprego. Nesses países são comuns os "observatórios universitários", responsáveis por acompanhar a trajetória de seus estudantes, bem como seus desempenhos na vida profissional (PAUL, 2015).

No Brasil, ainda que se desenvolvam relevantes pesquisas acadêmicas sobre a avaliação e perfil dos egressos (LIMA; ANDRIOLA, 2018; FRANCISCO et al., 2016; SOUTO, 2016; PEREIRA et al., 2016; RAMOS, 2016; IGLESIAS, 2016; TEIXEIRA et al., 2014; REGIO et al., 2014), as ações sistematizadas de acompanhamento continuam incipientes (SIMON; PACHECO, 2017; PAUL, 2015; QUEIROZ, 2014).

No contexto específico das engenharias, o número de trabalhos em revistas nacionais especializadas da área que analisam a avaliação dos egressos de graduação ainda se mostra escassas (SILVA, 1997; MACHADO, 2001; CAETANO; 2002; FERREIRA; CRISÓSTOMO, 2011; VASCONCELOS, 2012; SANTOS et al., 2015). Na literatura internacional a temática já possui uma vasta publicação, com destaques para os estudos de Zaharim et al. (2009) sobre a percepção das habilidades necessárias para o ingresso no mercado de trabalho da Malasia, Japão, Singapura e Hong Kong, de Atkinson e Pennington (2012) sobre as percepções do desemprego no Reino Unido, de Castro et al. (2017) sobre a empregabilidade de engenharios de computação na Filipinas, de Campbell et al. (2018) sobre as diferenças de rendas entre os graduados extrangeiros e nativos nos Estados Unidos,

Se considerar que se trata de um dos setores que mais reflete os impactos das conjunturas econômicas de um determinado período, a análise parece estratégica para a avaliação e planejamento dos atuais cursos superiores do país.

Neste sentido, o presente trabalho tem por objetivo avaliar os egressos oriundos das primeiras turmas dos cursos de Engenharia (2013-2017) de um Campus avançado da Universidade Federal de São João del Rei-MG. Propõe-se por meio de uma pesquisa 
quantitativa acompanhar a relação da inserção e reflexões das relações do mundo acadêmico com o mundo do trabalho, subsidiando a formação universitária.

Ademais, justifica-se o recorte empírico por se tratar de um contexto universitário recente, cuja criação do campus e dos respectivos cursos ocorreu em 2009, período marcado por tendências de expansão das universidades públicas brasileiras. Portanto, a natureza da avaliação pode contribuir para avaliar o perfil, a qualificação dos graduados, as dificuldades encontradas e oportunidades desenvolvidas durante a graduação (LOUSADA; MARTINS, 2005).

\section{Avaliação institucional no contexto do ensino superior}

A avaliação institucional é considerada um instrumento de relevância na busca da qualidade e eficiência na educação superior (LIMA; ANDRIOLA, 2018, SALLES, 2013). Através dela, a IES tem a oportunidade de refletir acerca de suas potencialidades, desafios e fragilidades, além de traçar, com maior clareza, um planejamento capaz de auxiliá-la no enfrentamento das ameaças e dificuldades. Para Scaglione (2013), a importância da avaliação institucional é inquestionável, visto que permite que as decisões tomadas estejam alinhadas à missão, visão e valores, além de ser uma prestação de contas à sociedade.

Dias Sobrinho (2010) aborda que a avaliação constitui ferramenta principal da organização e implementação das reformas educacionais. Para o autor, ela é capaz de possibilitar mudanças e adequações nos currículos, nas metodologias de ensino, nos conceitos e práticas de formação.

Outrossim, avaliação é vista como importante mecanismo para o planejamento das políticas estatais e para o controle dos recursos investidos e dos resultados alcançados na educação superior (ATKINSON; PENNINGTON, 2012; OLIVEIRA, et al., 2013). É através dela que o Estado tem um retorno da atuação da IES e da qualidade dos cursos superiores ofertados. Além disso, os resultados das avaliações são fundamentais nos processos de credenciamento de instituições, autorização e reconhecimento de cursos (BRASIL, 2004).

Segundo Ramos (2016), no Brasil, os primeiros sistemas avaliativos da educação superior surgiram no início da década de 1960, durante o regime militar. Polidori (2009) afirma que, ao longo do tempo, houve significativas mudanças nos formatos de avaliação, especialmente nas últimas décadas.

\footnotetext{
As duas últimas décadas apresentam mudanças radicais no seu formato, principalmente em relação à sua concepção. De uma avaliação totalitária e que primava pelo ranqueamento, passou para um processo que respeita as diversidades e as especificidades das Instituições de Educação Superior (IES), momento em que foi
} 
instituído o Sistema Nacional de Avaliação da Educação Superior, o SINAES (POLIDORI, 2009, p. 439).

O Sistema Nacional de Avaliação Superior - SINAES, instituído em 2004 pela Lei no 10.861, contempla de forma integrada a avaliação das IES, dos cursos de graduação e do desempenho acadêmico de seus estudantes. Para Coelho e Oliveira (2012), o sistema trouxe uma inovação ao considerar os egressos como elemento importante no processo de avaliação e planejamento.

Entre as 10 dimensões que o SINAES avalia, a nona faz referência à "política de atendimento ao estudante" (Lei $\mathrm{n}^{\circ} 10.861 / 2004$, art. $3^{\circ}$, IX). Consoante com Lousada e Martins:

\begin{abstract}
O estudo de acompanhamento de egressos pode ser inserido nesse contexto da avaliação institucional, como um componente que irá auxiliar no apontamento da realidade qualitativa da IES, como uma das formas de avaliação de produtos ou resultados, ou seja, vai conferir significado à avaliação dos cursos, quanto a sua respeitabilidade, desempenho, qualidade e, até mesmo, quanto ao seu prestígio externo (LOUSADA; MARTINS, 2005, p. 76).
\end{abstract}

Segundo Espartel (2009), Lima e Andriola (2018), os egressos podem fazer uma avaliação mais consistente sobre o curso, na medida em que são capazes de verificar, de forma prática, a contribuição do curso para sua atuação profissional. Além do retorno quanto à aprendizagem e sua aplicabilidade, o egresso retoma outras questões como a absorção pelo mercado, a satisfação profissional, o perfil do profissional formado. O conhecimento desses elementos permite à IES um processo de autocrítica, fornecendo subsídios para a avaliação e melhoria da qualidade dos processos de ensino-aprendizagem, das práticas pedagógicas e de gestão universitária.

\title{
3 Estudos avaliativos com os egressos
}

Os estudos realizados com egressos do ensino superior no Brasil aduzem a sua importância, seja para a sociedade, para a instituição, ou para profissional formado. Segundo Schwartzman e Castro (1991), Lima e Andriola (2018), as pesquisas com egressos recuperam diversas questões, especialmente as que dizem respeito à adequação dos currículos à situação profissional.

Para Michelan et al. (2009), os principais motivos que justificam a realização de estudos sobre egresso são a oportunidade de se obter uma avaliação da IES na perspectiva de quem já se formou, ao conhecer o perfil social e a trajetória profissional dos egressos; compreender as facilidades e dificuldades na inserção do egresso no mercado de trabalho, bem como, promover adequações necessárias nos currículos e programas políticos-pedagógicos. 
De modo similar, Iglesias (2016) aponta que o estudo com egressos se mostra importante por possibilitar a avaliação da inserção e condições de atuação dos profissionais, por prover elementos para a reestruturação dos currículos da IES, além da manutenção do vínculo entre o egresso e a IES.

Ao se considerar tais apontamentos, depreende-se que o acompanhamento do egresso se mostra como ferramenta capaz de viabilizar inúmeras contribuições à IES. Entre outros aspectos, as informações podem ser utilizadas para reflexão e avaliação da qualidade e adequação dos processos de ensino-aprendizagem para implementação contínua de melhorias (CISLAGHI et al., 2015; LOUSADA; MARTINS, 2005).

Para Machado (2010, p. 303), as informações advindas de pesquisas com egressos podem ser utilizadas como "instrumentos de planejamento e de gestão, em especial para a melhoria da qualidade das políticas institucionais voltadas ao ensino e ao atendimento dos estudantes". Nesse mesmo sentido, Lousada e Martins (2005) apontam o sistema de acompanhamento de egressos como uma ferramenta para se estabelecer e desenvolver estratégias para melhoramento da gestão.

Ademais, o egresso pode ser visto como fonte primordial de informações e críticas ao curso, visto que ele poderá, efetivamente, confrontar as competências e habilidades desenvolvidas durante o curso com as requeridas no exercício da profissão (MEIRA; KURCGANT, 2009).

Melo Filho (2014) sublinha que o acompanhamento de egressos deve ser parte integrante das práticas educacionais, uma vez que contribui para a reavaliação das políticas educacionais e institucionais. Destaca, ainda, alicerçado em Hoyos, que os egressos são referências para os indicadores de uma IES. Assim:

\footnotetext{
Quem pensa que quem credencia uma boa universidade são seus "campi", seus edifícios, laboratórios, e até mesmo sua biblioteca, está equivocado. Nem sequer são seus professores e os alunos. O que credencia uma boa universidade é o produto, a ciência, os egressos. Se existem excelentes egressos, existe uma excelente Universidade (HOYOS, 1998 apud MELO FILHO, 2014, p. 61-62).
}

Outro aspecto propiciado pelo acompanhamento do egresso diz respeito à educação continuada. Segundo Regio et al. (2014), os egressos podem indicar suas expectativas de educação continuada e, com isso, contribuir com a escolha de cursos de formação complementar a serem ofertados. Nessa ótica, a formação do estudante não se encerra no momento da conclusão do curso, mas se perpetua ao longo da sua vida profissional, evitandose a obsolescência do conhecimento frente às constantes mudanças que ocorrem na sociedade e no mercado de trabalho (MACHADO, 2010). 


\section{Metodologia}

Neste trabalho a natureza da pesquisa se classifica como aplicada, cujo escopo é exploratória, entendida pela investigação que tem por objetivo proporcionar a visão geral sobre um determinado fato. Este tipo de pesquisa é executado quando o tema escolhido é pouco explorado, dificultando assim a formulação de possíveis hipóteses que justifiquem as relações encontradas do objeto em estudo (GIL, 2002).

Quanto à estratégia de pesquisa, o projeto foi baseado no estudo de caso. Segundo Roesch (1999), possibilita uma análise em diversos ângulos sobre o ambiente no qual a amostra está inserida. O caso investigado se tratou da avaliação de três cursos oriundos do UFSJ-Campus Sete Lagoas que já diplomaram seus estudantes: Engenharia Agronômica, Engenharia de Alimentos e Bacharelado Interdisciplinar em Biossistemas.

No período de fevereiro a dezembro de 2017 buscou-se investigar todos os egressos, cujo universo é de 184 sujeitos, sendo Engenharia Agronômica 45,7\% (84 concluintes), seguido pela Engenharia de Alimentos 40,2\% (74 concluintes) e pelo Bacharelado Interdisciplinar em Biossistemas (BIB) 4,9\% (9 concluintes). Somente 9,2\% (17 concluintes) tiveram dupla formação (Engenharia de Alimentos ou Agronômica junto com Bacharelado Interdisciplinar em Biossistemas).

No que se refere à técnica de coleta de dados, foi utilizada a consulta ao acervo de dados da Divisão de Acompanhamento e Controle Acadêmico Interno, entre os anos de 2009 a 2017, com o intuito de mapear e comparar a relação de todos os alunos em curso e dos egressos da UFSJ -Campus de Sete Lagoas. O acervo de banco de dados foi constituído de informações socioculturais das matrículas dos estudantes, com informações obtidas no período de ingresso e atualizadas durante a conclusão do curso, por parte da instituição.

Em seguida, realizou-se entrevistas estruturadas com os egressos que podem ser definidas pela técnica que busca a produção de dados e informações por meio de um roteiro com perguntas norteadoras, possibilitando novos questionamentos durante a investigação (GIL, 2002). Em termos analíticos, por meio do uso de uma pesquisa quantitativa, aplicou-se questionários com os egressos, cujo meio de comunicação utilizado foi e-mail, Facebook, WhatsApp e ligações por telefone. O período de aplicação dos questionários foi do dia 1 de agosto a 20 de outubro de 2017. Foram enviados 184 questionários, sendo que 133 responderam, o que representa $72,3 \%$ do universo dos egressos. Os números de respondentes se mostram significativos em comparações com pesquisas da mesma natureza que ilustram baixa adesão à resposta, com média de retorno de 30\% a 50\% (FRANCISCO et al., 2016). 
Quanto à análise dos dados gerados pela pesquisa quantitativa, foi utilizado o Software estatístico SPSS (Statistical Package for the Social Sciences), que possibilitou por meio de ferramentas estatísticas descritivas, transformar os dados quantitativos em informações relevantes em função da compreensão do tema. Por fim, enquanto categorias de análise, o estudo avaliou: (I) o perfil sóciocultural e desempenho acadêmico dos egressos; (ii) a inserção no mercado de trabalho; (iii) a percepção das condições competitivas no mercado; e (iv) a avaliação da formação proporcionada pela instituição superior.

\section{Análise e discussão dos resultados}

\subsection{Perfil sociocultural e desempenho acadêmico}

Uma análise do desempenho dos discentes da UFSJ-CSL, no período da criação do Campus - 2009 até o primeiro semestre de 2017, aponta para a oferta de 1820 vagas, sendo que o índice de alunos matriculados foi de 44,8\% (817 alunos), de evasão 45,0\% (819 alunos) e alunos que colaram grau de apenas 22,0\% (184 alunos).

Ao comparar a realidade do estudo com os dados atuais do Instituto Nacional de Pesquisas Educacionais Anísio Teixeira (INEP, 2017), observa-se que enquanto o número total de mátriculas no ensino superior do país no ano de 2017 foi de 11.440 .726 , o percentual de evasão registrado indicou $17 \%$ (2.029,687), o que torna a realidade do Campus Sete Lagoas acima da média nacional. Uma hipótese para a discrepância pode ocorrer pela tradição dos cursos de engenharias, que apresentam um nível de exigência acadêmico bastante elevado em comparação com outras áreas do saber. No entanto, a restrita quantidade de trabalhos acadêmicos que discutem o perfil dos egressos desta natureza, impossibilitam comparações e inferências.

Na UFSJ- CSL, os egressos que se declaram preto/pardo/indígena foram apenas 11,4\% (21), sendo branco/oriental 14,1\% (26) e não declarados 74,5\% (137). Em vista da declaração de raça ser um item optativo durante a matrícula, os dados impossibilitam maiores conclusões sobre a comparação do Campus em relação a realidade nacional.

No que se refere ao gênero, 69,0\% (126) dos egressos da UFSJ-CSL são mulheres e 31,0\% (58) homens. Ao realizar uma comparação do coeficiente de rendimento acadêmico dos egressos em relação ao gênero, é possível observar que as mulheres não só representa o maior número, algo recente no contexto dos cursos de engenharia (SANTOS et al., 2015), como também registrou melhor desempenho acadêmico com a média de coeficiente de rendimento de 7,45 em comparação com os homens, 7,09. 
Em similaridade, os dados do Inep (2017) indicam que dos 8 milhões de alunos cursando o ensino superior do país, as mulheres representam 58\% do total de matrículas, enquanto os homens $42 \%$. Estes números aumentam quando se trata dos concluintes, na qual as mulheres saltam para $61 \%$ em comparação com $39 \%$ do sexo masculino.

Em relação ao estado de origem, 93,5\% (172) dos egressos da UFSJ-CSL são de Minas Gerais, sendo que os demais estados representam apenas 6,5\% (12). A realidade do Campus parece ilustrar o caráter da regionalidade das universidades públicas do país. Resultados similares foram encontrados na pesquisa de Santos et al. (2015), Lima e Andriola (2018), ao analisarem o perfil de mil egressos de uma universidade do Ceará. Observou-se o fenômeno da sua regionalização, na qual mais de $95 \%$ são e residem no mesmo estado em que cursaram o ensino superior.

Quanto a idade e o estado civil dos egressos, a média de idade no momento da colação de grau era de 25 anos, o que caracteriza um público jovem, por serem as primeiras turmas do Campus que colaram grau entre os anos de 2013 a 2017. A idade também se relaciona com o estado civil dos egressos, na qual 86,5\% (115) se declararam solteiros e apenas 13,5\% (18) casados. Uma comparação com o censo do registro civil do IBGE indica uma consonância com a realidade nacional, na qual as mulheres se casam pela primeira vez, em média, aos 27 anos e os homens aos 30 IBGE (2015).

\subsection{Inserção no mercado de trabalho}

Feita a caracterização do perfil e desempenho dos egressos, a segunda parte da pesquisa foi realizada com base nas respostas obtidas pelo questionário online. Buscou-se assim, compreender se os egressos deram continuidade ao processo formativo por meio de pósgraduações. Constatou-se que 69,2\% (75 concluintes) tentaram algum processo seletivo na área de ensino, sendo a maioria do curso de Bacharelado Interdisciplinar em Biossistemas (BIB) 83,3\%, seguido pela Engenharia Agronômica 67,7\% e Engenharia de alimentos 41,9\% (Tabela 1). O percentual elevado nos dois primeiros cursos pode ter justificativas no fato da UFSJ-CSL ter um programa de Mestrado em Ciências Agrárias e parcerias com a Empresa Brasileira de Pesquisa Agropecuária (EMBRAPA) e Empresa de Pesquisa Agropecuária em Minas Gerais (EPAMIG), o que tende a abrir oportunidades de continuidade dos estudos. No entanto, a falta de outros dados sistematizados sobre o perfil das engenharias, dificulta a comparação e conclusões encontradas nesta pesquisa. 
Tabela 1 - Processo seletivo na área de ensino tentado pelos egressos da UFSJ-CSL

\begin{tabular}{ccccccc}
\hline & \multicolumn{3}{c}{ Frequência } & & \multicolumn{3}{c}{ Percentual (\%) } \\
\hline & Sim & Não & Total & Sim & Não & Total \\
\hline $\begin{array}{c}\text { Interdisciplinar em Biossistemas } \\
\text { Engenharia Agronômica }\end{array}$ & 5,0 & 1,0 & 6,0 & 83,3 & 16,7 & 100,0 \\
Engenharia de Alimentos & 26,0 & 36,0 & 62,0 & 41,9 & 58,1 & 100,0 \\
\hline Total & $\mathbf{7 5 , 0}$ & $\mathbf{4 8 , 0}$ & $\mathbf{1 3 3 , 0}$ & $\mathbf{6 9 , 2}$ & $\mathbf{3 0 , 8}$ & $\mathbf{1 0 0 , 0}$ \\
\hline
\end{tabular}

Fonte: Banco de dados formado pelas respostas dos questionários, 2018.

A pergunta subsequente foi destinada aos egressos que tentaram e passaram no processo seletivo, de modo que se questionou: Se sim, qual, com as opções para especialização, mestrado e ou doutorado?

Dos egressos do BIB $80 \%$ estão fazendo ou já fizeram o mestrado, e $20 \%$ já concluíram o mestrado e estão no doutorado. Já dos Engenheiros Agrônomos, 75\% foram para o mestrado, $22,7 \%$ foram para o doutorado após a conclusão do mestrado e 11,4\% fizeram apenas especialização (Tabela 2).

Tabela 2 - Pós-graduação dos egressos da UFSJ-CSL

\begin{tabular}{ccccccccc}
\hline & \multicolumn{9}{c}{ Frequência } & & & & Percentual (\%) \\
& BIB & $\begin{array}{c}\text { Eng } \\
\text { Agro }\end{array}$ & $\begin{array}{c}\text { Eng } \\
\text { Alim }\end{array}$ & Total & BIB & Eng Agro & Eng Alim & Total \\
\hline Mestrado & 3,0 & 33,0 & 18,0 & 54,0 & 80,0 & 75,0 & 66,7 & 60,6 \\
Doutorado & 1,0 & 10,0 & 4,0 & 15,0 & 20,0 & 22,7 & 14,8 & 16,9 \\
Especialização & 0,0 & 5,0 & 8,0 & 13,0 & 0,0 & 11,4 & 29,6 & 14,6 \\
Não passou & 1,0 & 5,0 & 1,0 & 7,0 & 20,0 & 11,4 & 3,7 & 7,9 \\
\hline Total & $\mathbf{5 , 0}$ & $\mathbf{5 3 , 0}$ & $\mathbf{3 1 , 0}$ & $\mathbf{8 9 , 0}$ & $\mathbf{1 2 0 , 0}$ & $\mathbf{1 2 0 , 5}$ & $\mathbf{1 1 4 , 8}$ & $\mathbf{1 0 0 , 0}$ \\
\hline
\end{tabular}

Fonte: Banco de dados formado pelas respostas dos questionários, 2017.

Ao estabelecer uma comparação com o total de respondentes de cada curso, a Engenharia Agronômica e o BIB têm destaque na área acadêmica, pois, mais da metade dos egressos seguiram a área (mestrado e doutorado). Na Engenharia de Alimentos, apenas 29,60\% do total de 62 egressos indicou continuidade na área acadêmica (mestrado e doutorado), o que 
parece indicar um perfil de profissional mais voltado para a indústria ou iniciativas de empreendedorismo individual.

Outro dado relevante foi o baixo percentual de reprovação nos processos seletivos na área de ensino. O curso com maior percentual de reprovação foi o BIB, com 20,0\%. Isso pode ser explicado pelos poucos respondentes, foram apenas 6, tornando o dado pouco representativo. A Engenharia de Alimentos teve o menor percentual de reprovação, com apenas 3,7\%, enquanto na Engenharia Agronômica foi de 11,4\%, o que indica também um percentual baixo.

Da mesma forma, ao questionar o tempo que se gastou para ingressar nos processos seletivos da área de ensino (especialização, mestrado, doutorado), registrou-se que os egressos tiveram rápido acesso nas instituições de pós-graduação. Se considerar o intervalo de tempo de 1-12 meses, tem-se 97,3\% dos alunos da Engenharia Agronômica e 82,7\% dos graduados da Engenharia de Alimentos, enquanto no BIB 100,0\% ingressaram entre o período de 1-6 meses (Tabela 3). Os dados referentes ao baixo índice de reprovação e rápido acesso aos processos seletivos, podem servir como um indicador de avaliação dos cursos da Instituição UFSJ, no campo da pesquisa e ensino.

Tabela 3 - Tempo de ingresso dos egressos da UFSJ-CSL na pós-graduação

\begin{tabular}{ccccccccc}
\hline & \multicolumn{3}{c}{ Frequência } & \multicolumn{4}{c}{ Percentual (\%) } \\
\hline & \multirow{2}{*}{ BIB } & $\begin{array}{c}\text { Eng } \\
\text { Agro }\end{array}$ & $\begin{array}{c}\text { Eng } \\
\text { Alim }\end{array}$ & Total & \multirow{2}{*}{ BIB } & Eng Agro & Eng Alim & Total \\
\hline 1 1-6 meses & 3,0 & 31,0 & 17,0 & 51,0 & 100,0 & 83,8 & 73,9 & 81,0 \\
$6-12$ meses & 0,0 & 5,0 & 2,0 & 7,0 & 0,0 & 13,5 & 8,7 & 11,1 \\
$12-18$ meses & 0,0 & 0,0 & 1,0 & 1,0 & 0,0 & 0,0 & 4,3 & 1,6 \\
$18-24$ meses & 0,0 & 1,0 & 3,0 & 1,0 & 0,0 & 2,7 & 13,1 & 6,3 \\
\hline Total & $\mathbf{3 , 0}$ & $\mathbf{3 7 , 0}$ & $\mathbf{2 3 , 0}$ & $\mathbf{6 3 , 0}$ & $\mathbf{1 0 0 , 0}$ & $\mathbf{1 0 0 , 0}$ & $\mathbf{1 0 0 , 0}$ & $\mathbf{1 0 0 , 0}$ \\
\hline
\end{tabular}

Fonte: Banco de dados formado pelas respostas dos questionários, 2017.

Referente à situação dos egressos que buscaram processos seletivos no mercado de trabalho, observou-se que no curso de Engenheiros de Alimentos, a grande maioria $(83,9 \%)$ tentou algum processo seletivo, enquanto na Engenharia Agronômica foram 63,1\%, e no BIB, o percentual caiu consideravelmente para $16,7 \%$ (Tabela 4). 
Tabela 4 - Tentativas de inserção dos egressos da UFSJ-CSL no mercado de trabalho

\begin{tabular}{ccccccc}
\hline & \multicolumn{3}{c}{ Frequência } & \multicolumn{3}{c}{ Percentual (\%) } \\
\hline & Sim & Não & Total & Sim & Não & Total \\
\hline Engenharia de Alimentos & 52,0 & 10,0 & 62,0 & 83,9 & 16,1 & 100,0 \\
Engenharia Agronômica & 41,0 & 24,0 & 65,0 & 63,1 & 36,9 & 100,0 \\
Interdisciplinar em Biossistemas & 1,0 & 5,0 & 6,0 & 16,7 & 83,3 & 100,0 \\
\hline Total & $\mathbf{9 4 , 0}$ & $\mathbf{3 9 , 0}$ & $\mathbf{1 3 3 , 0}$ & $\mathbf{6 9 , 2}$ & $\mathbf{3 0 , 8}$ & $\mathbf{1 0 0 , 0}$ \\
\hline
\end{tabular}

Fonte: Banco de dados formado pelas respostas dos questionários, 2017.

Os dados parecem corroborar a hipótese de que as formações dos egressos dos três cursos apresentam perfis distintos, conforme visto anteriormente. Enquanto a Agronomia e o BIB tenderam a uma perspectiva de atuação na área do ensino e pesquisa, na Engenharia de Alimentos o perfil parece mais voltado para o campo industrial. No entanto, deve-se considerar que alguns egressos buscaram ambas as atuações (dos 63 egressos que fizeram a pós-graduação, $46 \%$ (29) tentaram algum processo seletivo), principalmente porque a realização de uma especialização ou mestrado, não implica necessariamente em seguir uma vida acadêmica ou de pesquisa.

Referente ao percentual de inserção no mercado de trabalho observou-se que apenas metade dos egressos está atuando dentro da sua área de formação. Pois, da Engenharia de Alimentos são 53\% e Engenharia Agronômica 48,8\% (Tabela 5), o que parece atualmente refletir a realidade dos altos índices de desempregos no Brasil.

Em consonância, os estudos de Regio et al. (2014) ao analisar o perfil de 121 egressos do curso de Administração da Universidade Federal de Santa Maria, apontou que no ano de 2012, ainda no apíce da empregabilidade no país, apenas 47,1\% estavam exercendo a profissão. Em similaridade, o estudo de Souto (2016) com egressos do curso de licenciatura em matemática indicou que 53\% não estão exercendo e não pretende continuar na profissão, em decorrência do sentimento de desvalorização profissional e más condições de trabalho.

Não é por menos que para Pereira et al. (2016) o substancial aumento do número de egressos no Brasil representa melhorias em termos de democratização do ensino superior, no entanto, o avanço vem acompanhado da desvalorização da mão de obra qualificada, do decréscimo no número de empregos de maior remuneração, e consequente déficits de emprego de nível superior. 
Tabela 5 - Inserção dos egressos da UFSJ-CSL no mercado de trabalho

\begin{tabular}{cccccccccc}
\hline & \multicolumn{3}{c}{ Frequência } & \multicolumn{5}{c}{ Percentual (\%) } \\
\hline & BIB & $\begin{array}{c}\text { Eng } \\
\text { Agro }\end{array}$ & $\begin{array}{c}\text { Eng } \\
\text { Alim }\end{array}$ & Total & BIB & $\begin{array}{c}\text { Eng } \\
\text { Agro }\end{array}$ & $\begin{array}{c}\text { Eng } \\
\text { Alim }\end{array}$ & Total \\
\hline $\begin{array}{c}\text { Tentou algum processo seletivo no } \\
\text { mercado de trabalho }\end{array}$ & 1,0 & 41,0 & 52,0 & 94,0 & 16,7 & 63,1 & 83,9 & 70,7 \\
$\begin{array}{c}\text { Está atuando na sua área de formação } \\
\text { no mercado }\end{array}$ & 0,0 & 20,0 & 28,0 & 48,0 & 0,0 & 48,8 & 53,8 & 51,0 \\
$\begin{array}{c}\text { Não está atuando na sua área de } \\
\text { formação no mercado }\end{array}$ & 1,0 & 21,0 & 24,0 & 46,0 & 100,0 & 51,2 & 46,2 & 49,0 \\
\hline
\end{tabular}

Fonte: Banco de dados formado pelas respostas dos questionários, 2017.

Em similaridade as observações registradas por Pereira et al. (2016), na presente pesquisa, ao investigar a média salarial daqueles que estão no mercado, observou-se que dos egressos da Engenharia Agronômica, 35,0\% recebem de 1-4 salários mínimos e na Engenharia de Alimentos esse percentual é a maioria, subindo para 85,7\%. Já os salários de 6-8, 8-10 e 1012 salários mínimos, não tem nenhum graduado em Engenharia de Alimentos, sendo apenas relatados pelos ex-alunos da Engenharia Agronômica (Tabela 6).

Além da substancial diferença de remuneração entre os dois cursos, em ambos os casos, a maioria dos egressos não estão recebendo o mínimo (piso) estabelecido pelo Conselho Regional de Engenharia e Agronomia (CREA, 2017) que é de seis salários mínimos para os Engenheiros recém-formados no Brasil.

Tabela 6 - Média salarial dos egressos da UFSJ-CSL

\begin{tabular}{ccccccc}
\hline & \multicolumn{3}{c}{ Frequência } & \multicolumn{3}{c}{ Percentual (\%) } \\
\hline & Eng. Agro & Eng. Alim & Total & Eng. Agro & Eng. Alim & Total \\
\hline 1-2 salários mínimos & 3,0 & 7,0 & 10,0 & 15,0 & 25,0 & 20,8 \\
2-4 salários mínimos & 4,0 & 17,0 & 21,0 & 20,0 & 60,7 & 43,8 \\
4-6 salários mínimos & 6,0 & 4,0 & 10,0 & 30,0 & 14,3 & 20,8 \\
6-8 salários mínimos & 2,0 & 0,0 & 2,0 & 10,0 & 0,0 & 4,2 \\
8-10 salários mínimos & 4,0 & 0,0 & 4,0 & 20,0 & 0,0 & 8,3 \\
10-12 salários mínimos & 1,0 & 0,0 & 1,0 & 5.0 & 0,0 & 2,1 \\
\hline Total & 20,0 & 28,0 & 48,0 & 100,0 & 100,0 & 100,0 \\
\hline
\end{tabular}

Fonte: Banco de dados formado pelas respostas dos questionários, 2017.

Em uma comparação com as pesquisas sobre os engenheiros no Brasil na década de 1990, é possível notar a perda salarial em comparação com o número de salários recebidos. O estudo de Silva (1997) e Machado (2001) que analisaram a média salarial de dos engenheiros 
recém formados da área de Cartografia, Eletrônica e Eletrotécnica do Brasil, constataram que nos anos de 1995 e 1996, a média salarial da categoria era de aproximadamente 19 salários mínimos. Mesmo o aumento do poder de compra do salário mínimo nestas décadas, estas diferenças, não camuflam as recentes perdas salariais da categoria de engenheiros.

Já em estudos mais recente sobre os Egressos de Engenharia, observou-se que no ano de 2009, período de estabilidade econômica nacional, Ferreira e Crisóstomo (2012) e Vasconcelos (2012), constataram que os egressos da área de metalurgia e engenharia de produção recebiam em média 11 salários mínimos, enquanto a pesquisa de Santos et al. (2015), já no início da recessão econômica, observou que os profissionais formados em engenharia Florestal recebiam remuneração inferior ao salário mínimo profissional da categoria no ano de 2015.

Referente às remunerações entre o gênero pela média salarial, fica notável a diferença de remuneração dos homens para as mulheres. Enquanto 81,2\% das mulheres recebem de 1-4 salários mínimos, esse percentual caiu para $21,3 \%$ entre os homens. $\mathrm{O}$ maior percentual dos homens está entre 4-6 salários mínimos, com 31,2\%, enquanto no gênero feminino o percentual decresce para $15,6 \%$.

Ademais, não se registrou nenhuma mulher graduada recebendo mais de oito salários mínimos, sendo que 31,2\% dos homens estão recebendo esse valor. Apesar dos dados serem alarmantes, pois as egressas apresentam maior desempenho acadêmico durante o curso e representam $70 \%$ dos concluintes, as desigualdades entre os gêneros, ilustram também a realidade evidenciada por recentes pesquisas.

Os estudos de Teixeira et al. (2014) sobre os egressos de biologia de três instituições públicas do Estado do Rio de Janeiro, apontaram que as mulheres, embora sejam maioria no mercado profissional de Ciências Biológicas, apresentaram menores rendas que os homens. Isto ilustra que apesar de terem conquistado espaço, elas ainda estão na base da pirâmide de renda.

Em similaridade, os dados do IBGE de 2018 apontam que as mulheres trabalham em média, três horas a mais por semana do que os homens, combinando trabalhos remunerados, afazeres domésticos e cuidados de pessoas. Mesmo assim, e ainda com um nível educacional mais alto, elas ganham, em média, 76,5\% do rendimento dos homens (AGÊNCIA IBGE NOTÍCIAS, 2018). 


\subsection{Percepção das condições competitivas no mercado}

A terceira etapa da pesquisa teve por objetivo avaliar a percepção que os egressos tiveram de sua graduação, e das consequentes possibilidades e limitações de inserção no mercado. Para tal, a primeira questão foi direcionada aos egressos que ingressaram no mercado de trabalho e/ou nos processos seletivos de pós-graduação. Logo, da amostra de 133 questionários, apenas 84 responderam essa pergunta. Dos respondentes, a grande parcela afirmou que a iniciação científica $(25,0 \%)$, o estágio $(23,8 \%)$, a dedicação $(15,5 \%)$ e a participação de eventos científicos $(10,7 \%)$ foram essenciais para que conseguissem atingir os objetivos. Os dados parecem ilustrar que na visão dos egressos, a instituição teve contribuição na formação profissional, ainda que as dimensões individuais como a dedicação $(15,5 \%)$, e fatores externos (Estágio - 23,8\%), contribuíram para a sua formação (Tabela 7).

\section{Tabela 7 - Itens que foram essências durante a graduação para atingir os objetivos}

\begin{tabular}{ccc}
\hline & Frequência & Percentual (\%) \\
\hline Iniciação cientifica & 21,0 & 25,0 \\
Estágio & 20,0 & 23,8 \\
Dedicação & 13,0 & 15,5 \\
Participação em eventos científicos & 9,0 & 10,7 \\
Conhecimento adquirido na universidade & 8,0 & 9,5 \\
Cursos extracurriculares & 3,0 & 3,6 \\
Outros & 10,0 & 11,9 \\
\hline Total & 84,0 & 100,0 \\
\hline
\end{tabular}

Fonte: Banco de dados formado pelas respostas dos questionários, 2017.

No que se refere aos egressos que não estão atuando na sua área de formação, foi questionado as possíveis razões de não estarem na área de formação. Observou-se que dos Engenheiros Agrônomos, 62,0\% abordaram a falta de vaga no mercado, 28,5\% estavam completando estudo, $14,3 \%$ em outra formação profissional, $9,5 \%$ mudança de interesse e 4,8\% encontraram melhores oportunidades fora da área.

Já os Engenheiros de Alimentos, 63,3\% apontaram a falta de vaga no mercado de trabalho, 27,2\% completando estudo, 22,7\% encontraram melhores oportunidades fora da área, 18,2\% mudaram de interesse e 4,5\% em outra formação profissional. No caso do BIB apenas 1 egresso do BIB afirmou não atuar na área devido a melhores oportunidades fora dela (Tabela 8). 
Tabela 8 - Possíveis razões para os egressos da UFSJ-CSL não estarem atuando na sua área de formação

\begin{tabular}{ccccccc}
\hline & \multicolumn{3}{c}{ Frequência } & \multicolumn{3}{c}{ Percentual (\%) } \\
\hline & Eng. & Eng. & BIB & Eng. & Eng & BIB \\
& Alim & Agro & & Alim & Agro & \\
\hline Falta de vaga no mercado & 13,0 & 14,0 & 0,0 & 63,3 & 62,0 & 0,0 \\
Completando estudo & 16,0 & 6,0 & 0,0 & 27,2 & 28,5 & 0,0 \\
Outra formação profissional & 3,0 & 1,0 & 0,0 & 22,7 & 14,3 & 0,0 \\
Mudança de interesse & 2,0 & 3,0 & 0,0 & 18,2 & 9,5 & 0,0 \\
Melhores oportunidades fora da área & 1,0 & 4,0 & 1,0 & 4,5 & 4.8 & 100,0 \\
\hline
\end{tabular}

Fonte: Banco de dados formado pelas respostas dos questionários, 2017.

Os dados parecem refletir a atual crise econômica da sociedade brasileira, cujo desemprego na visão dos egressos não é necessariamente limitação da qualificação ou do processo formativo da universidade, mas ocasionados pela falta de vagas no mercado de trabalho. Segundo o IBGE (2017), no $4^{\circ}$ trimestre de 2017, a taxa de subutilização da força de trabalho (aqueles que fazem parte da força de trabalho potencial) ficou em 23,8\%, o que representa 26,4 milhões de pessoas desocupadas ou subocupados por insuficiência de horas. A realidade fortalece a hipótese da pesquisa de Pereira et al. (2016), na qual o aumento de concluintes no nível superior do país não vem acompanhado de novos postos de trabalho.

Referente às questões de empregabilidade, foi questionado aos egressos fora do mercado, o que precisavam para que atingir aos objetivos profissionais. As respostas reforçaram os argumentos anteriores, de modo que para 39,2\% dos concluintes trata-se de maiores oportunidades no mercado, seguido de mais experiência na área de atuação 23,5\% e 9,9\% mais dedicação (Tabela 9). Semelhanças foram encontradas na pesquisa de Santos et al. (2015), na qual 72,2\% dos egressos de engenharia Florestal que não conseguiram inserir no mercado, atribuíram as faltas de oportunidades como o principal fator.

Se considerar que a experiência profissional relatada por $23,5 \%$ dos egressos é algo que se obtêm inserido no mercado de trabalho, o problema da empregabilidade ilustra um ciclo vicioso, cuja exclusão no mercado de engenharia não permite a experiência e qualificação necessária para as vagas disponíveis. 
Tabela 9 - O que faltou para os egressos da UFSJ-CSL para atingirem os objetivos traçados

\begin{tabular}{ccc}
\hline & Frequência & Percentual (\%) \\
\hline Mais oportunidades no mercado de trabalho & 20,0 & 39,2 \\
Experiência na área de atuação & 12,0 & 23,5 \\
Ter mais Dedicação & 5,0 & 9,9 \\
Estudar mais & 4,0 & 7,8 \\
Inglês fluente & 4,0 & 7,8 \\
Ter realizado mais estágios & 3,0 & 5,9 \\
Outros & 3,0 & 5,9 \\
\hline Total & 51,0 & 100,0 \\
\hline
\end{tabular}

Fonte: Banco de dados formado pelas respostas dos questionários, 2017.

\subsection{Avaliação da instituição de ensino superior}

A última etapa da pesquisa buscou avaliar como os egressos refletiam sobre a formação obtida na instituição. Assim, ao questionar a formação na UFSJ- CSL em termos de inserção em comparação com outras instituições de ensino/ mercado de trabalho, observou-se que os índices foram satisfatórios para os egressos. Dentre as respostas, $54,1 \%$ afirmaram que a graduação possibilitou as mesmas oportunidades em comparação com os egressos de outras instituições, 22,6\% que as oportunidades foram melhores, e apenas 9,0\% avaliou como piores (Tabela 10).

Tabela 10 - Avaliação dos egressos da UFSJ-CSL em relação a instituição

\begin{tabular}{ccccccc}
\hline & \multicolumn{3}{c}{ Frequência } & \multicolumn{3}{c}{ Percentual (\%) } \\
\hline & $\begin{array}{c}\text { Eng. } \\
\text { Alim }\end{array}$ & $\begin{array}{c}\text { Eng. } \\
\text { Agro }\end{array}$ & BIB & $\begin{array}{c}\text { Eng. } \\
\text { Alim }\end{array}$ & $\begin{array}{c}\text { Eng. } \\
\text { Agro }\end{array}$ & BIB \\
\hline $\begin{array}{c}\text { A graduação possibilitou as mesmas } \\
\text { oportunidades que os concorrentes }\end{array}$ & 36,0 & 33,0 & 3,0 & 58,1 & 50,8 & 50,0 \\
$\begin{array}{c}\text { A graduação possibilitou melhores } \\
\text { oportunidades que os concorrentes }\end{array}$ & 11,0 & 18,0 & 1,0 & 17,7 & 27,7 & 17,0 \\
$\quad \begin{array}{c}\text { A graduação possibilitou piores } \\
\text { oportunidades que os concorrentes }\end{array}$ & 7,0 & 5,0 & 0,0 & 11,3 & 7,7 & 0,0 \\
Não sabe & 8,0 & 9,0 & 2,0 & 12,9 & 13,8 & 33,0 \\
\hline Total & 62,0 & 65,0 & 6,0 & 100,0 & 100,0 & 100,0 \\
\hline
\end{tabular}

Fonte: Banco de dados formado pelas respostas dos questionários, 2017.

Ainda que a opinião dos concluintes da UFSJ-CSL se limita a um curto período de tempo de experiência profissional, já que as primeiras turmas formaram em 2013, as respostas 
contribuem como um indicador de avaliação relevante para a instituição, por ilustrar que os altos índices de desempregos não são necessariamente atribuições da baixa qualificação, mas de questões macroeconômicas que interferem em todo o setor.

No sentido de refletir sobre essas questões, buscou-se indagar aos egressos o que considera importante a ser incluída na grade curricular e projeto pedagógico dos cursos para possibillitar melhorias para as futuras turmas. Constatou-se que grande parte dos egressos (120 respondentes), sugeriram estratégias que facilitassem a atuação nas iniciativas industriais e ou privadas. Assim, abordaram mais aulas práticas $(26,6 \%)$, parcerias com empresa privada $(17,5 \%)$, maior incentivo ao estágio $(7,5 \%)$, disciplinas de gestão empresarial, de pessoas e comercial $(7,5 \%)$ (Tabela 11$)$.

Tabela 11 - Sugestões dos egressos da UFSJ-CSL para trazer melhorias no mercado de trabalho

\begin{tabular}{ccc}
\hline & Frequência & Percentual (\%) \\
\hline Aulas práticas voltadas para o mercado & 32 & 26,6 \\
Parceria com empresa privada & 21 & 17,5 \\
Maior incentivo ao estágio & 9 & 7,5 \\
Disciplinas de gestão empresarial, de pessoas e comercial & 8 & 6,7 \\
Disciplinas de empreendedorismo & 3 & 2,5 \\
Melhor estrutura na grade curricular do curso & 3 & 2,5 \\
Mais cursos práticos & 3 & 2,5 \\
Outros & 41 & 34,2 \\
\hline Total & 120 & 100 \\
\hline
\end{tabular}

Fonte: Banco de dados formado pelas respostas dos questionários, 2017.

As respostas apresentam coerência com uma das dimensões da empregabilidade no mercado, a experiência profissional. Registra-se também, porém, em baixo percentual as sugestões da ênfase em disciplinas de gestão empresarial e/ou empreendedorismo como possível alternativa para lidar com a criação de vagas no mercado, voltadas para tendências da gestão da própria carreira.

Referente a esta última dimensão, um dos poucos trabalhos da literatura acadêmica que discute o perfil dos egressos das engenharias, em particular do curso de Engenharia de Alimentos, foi o estudo de Caetano (2002) que analisou os egressos da Unicamp nas décadas de 1990. Apesar de a realidade econômica da época ser muito distinta, em virtude do baixo número de engenheiros no mercado e da maior industrialização do segundo setor em 
comparação com a atualidade, a pesquisa apontava para reflexões nas grades curriculares que não mudaram muito. Dentre as considerações, há quase 20 anos, levantaram: (i) a necessidade de atividades relacionadas a conhecimentos de economia, marketing, administração e recursos humanos; (ii) e os aspectos relacionados à prática profissional que deveriam merecer maior atenção e destaque por parte dos formadores.

Para Caetano (2002), a grade curricular da engenharia contribuiu pouco para o desenvolvimento dos saberes da prática, de como entender o funcionamento real do processo, da capacidade de restabelecer bom relacionamento interpessoal.

Em uma visão mais profunda das interferências macroeconômicas nos cursos, chama a atenção que as sugestões voltadas para alternativas solidárias ou mesmo contestatórias às políticas econômicas do país, tampouco estiveram presente na percepção dos estudantes. O eixo central do emprego, visto como uma alternativa pela inclusão no segundo setor (industrialição), se situa na contramão da lógica de desindustrialização do país, que no ano de 2017 registrou apenas $11 \%$ do PIB do setor.

Neste sentido, Fraga (2006) sublinha que um dos desafios das grades curriculares das engenharias é lidar com suas atividades formativas para os ditos setores tradicionais, como ampliar as dimensões e compreensões técnologicas, a começar pela negação da neutralidade tecnológica, e da sua ressignificação para as demais atividades da sociedade. No entanto, para os autores, a via passa pela importância também pela formação de docentes com uma visão plural do papel da tecnologia, e que possibilite a atuação profissional para além dos setores convencionais.

\section{Considerações finais}

Diante das demandas por estudos voltados para a avaliação educacional, os egressos da graduação assumem papel estratégico para compreensão acerca da efetividade profissional dos conhecimentos adquiridos no período da formação. Na medida em que este público enfrenta, em seu cotidiano, situações complexas que levam a confrontar as competências desenvolvidas durante o curso com as requeridas no exercício profissional, tal vivência permite avaliar a adequação da estrutura pedagógica do curso e resgatar aspectos intervenientes do processo (LIMA; ANDRIOLA, 2018).

Ao traçar o perfil socio-cultural, desempenho acadêmico, dimensões da inserção profissional e avaliação da instituição na percepção dos egressos das primeiras turmas de engenharia da UFSJ, observou-se que os egressos fazem parte de apenas $23 \%$ dos alunos de 
colaram grau no Campus. Além disso, $69 \%$ são do gênero feminino, jovens, solteiros $(86,5)$ e oriundos do Estado de Minas Gerais $(93,5 \%)$.

Quanto à atuação profissional, observaram-se particularidades em cada um dos três cursos. Enquanto os egressos da Engenharia Agronômica (67,7\%) e Bacharelado Interdisciplinar $(83,3 \%)$ optaram por dar continuidade nos processos formativos, no curso de engenharia de Alimentos a maioria dos egressos $(83,9 \%)$ buscou a inserção no mercado empresarial.

O índice de aprovação nos processos seletivos de pós-graduação dos três cursos foi alto, registrando mais de $80 \%$ de inclusão. No entanto, a inserção no mercado de trabalho se mostrou bastante restritiva para os concluintes. Apenas metade está atuando na área de formação, Engenharia de Alimentos (53\%) e Engenharia Agronômica (48,8\%), o que parece refletir a realidade dos altos índices de desempregos no Brasil.

Dentre os egressos que conseguiram se empregar, em sua maioria, no entanto não recebem o mínimo estabelecido pelo Conselho Regional de Engenharia e Agronomia (CREA) que é de seis salários mínimos para os Engenheiros, sem considerar as substanciais diferenças de remuneração entre o gênero, o que coloca para a área os desafios da igualdade das mulheres no mercado de trabalho.

Por fim, as avaliações dos egressos em relação à instituição de ensino cursada foram positivas em comparação com outras instituições do setor, na qual para a maioria dos egressos que não estão atuando na área, atribuiu-se mais a falta de oportunidades no mercado $(62,5 \%$ dos respondentes), do que a fatores limitantes em seu processo formativo.

Ainda sim, enquanto sugestões de melhorias, as dimensões levantadas para a instituição se assemelhou ao estudo de Caetano (2002), cuja grade curricular da engenharia ilustrava limitações em não estabelecer suficientemente aulas práticas, parceria com empresa privada, maior incentivo ao estágio, disciplinas de legislação, gestão de pessoas, empresas e comercial.

Em vista do alto índice de rejeição no mercado de trabalho, os dados da presente pesquisa se mostram relevantes para avaliar as dificuldades e desafios encontrados pelos egressos que, pelos recentes acontecimentos políticos, estarão cada vez mais vulneráveis, em especial, as mulheres.

Com o fim dos investimentos públicos de cunho desenvolvimentista, a adoção de política de austeridade fiscal de cariz liberal, fomentadas por agências internacionais, como o Banco Mundial, a promoção do rentismo acrescida de uma agenda economica exportadora concetrada em commodities, intensificando o processo de desindustrialização brasileira, oferece uma perspectiva da perda do dinamismo econômico nacional. Não é o simples consumo que 
promove o aumento da capacidade produtiva, que alavanca o crescimento econômico, especialmente em tempos de crise, como também o investimento público, que tem sido substituído pelo discurso do estado mínimo.

Soma-se a isso a ocorrência da reforma trabalhista que legalizou tipos de contratações precárias e fragilizadas, permitindo que o negociado prevaleça sobre o legislado, articulada ao aprofundamentamento da ideologia do cidadão empreendedor. A possibilidade de formalização da atividade econômica pelos informais e trabalhadores por conta própria, por meio do registro como MEI - Microempreendedor Individual, implantado em 2009, teve como consequência adversa um crescimento fraudulento das relações de emprego e do acesso individualizado a direitos sociais, nocauteando a luta coletiva do trabalhador organizado em sindicatos. Esse cenário conta com um aumento progressivo e sistemático de desempregados e desalentados, que simplesmente desistem de procurar empregos, afetando especialmente os mais jovens.

Assim, o fomento de informações atualizadas, além de servir para a criação de indicadores dos cursos de engenharias e da própria gestão Universitária, permite um registro histórico capaz de orientar futuras políticas públicas que sejam mais efetivas ao desenvolvimento socieconômico e educacional do país.

Para concluir, colocam-se também reflexões emergentes para a área: Como a universidade pública pode lidar com os desafios impostos pelo desemprego e/ou precarização das condições de trabalho em seus projetos pedagógicos? As alternativas nas grades curriculares podem incentivar uma formação voltada para atuação em mercados ditos não convencionais, refletindo sobre as propostas de criações de associações e cooperativas de profissionais? As tendências do incentivo ao empreendedorismo e startups podem ser consideradas mecanismos efetivos de empregabilidade ou às contradições de um sistema de econômica mercantil prevalecerão, colocando em xeque, futuras profissões, que se sobreviverem, refletirão os processos de precarização do trabalho?

\section{Referências}

AGÊNCIA IBGE NOTICIAS. Estatísticas sociais: mulher estuda mais, trabalha mais e ganha menos. 2018. Disponível em: https://agenciadenoticias.ibge.gov.br/agencianoticias/2012-agencia-de-noticias/noticias/20234-mulher-estuda-mais-trabalha-mais-e-ganhamenos-do-que-o-homem.html. Acesso em: 13 maio 2018.

ATKINSON, H; PENNINGTON, M. Unemployment of engineering graduates: the key issues. Engineering Education, Camberra, v. 7, n. 2, 2012. 
BRASIL. Lei no 10.861, de 14 de abril de 2004. Institui o SINAES e dá outras providências. Disponível em: https://goo.gl/ETS63. Acesso em: 02 ago. 2017.

CAETANO, S. Contribuição à avaliação do curso de graduação da faculdade de engenharia de alimentos da Unicamp em face dos saberes da prática profissional de seus egressos.

Avaliação, Campinas, v. 2, n. 2, 2002.

CAMPBELL, T. A. et al. Employment and Earnings of International Science and Engineering Graduates of U.S. Universities: a comparative perspective. Journal of International Students, Baltimore, v. 6, n. 1, 2018.

CASTRO, E. et al. Employability of Computer Engineering Graduates during Academic Year 2015-2016 and their Lifelong Learning Options. Asia Pacific Journal of Academic

Research in Social Sciences, Batangas, v. 2, 2017. Disponivel em:

https://research.lpubatangas.edu.ph/wp-content/uploads/2018/12/Employability-of-ComputerEngineering-for-2016.pdf. Acesso em: 02 ago. 2018.

CISLAGHI, R. et al. Gestão de qualidade de cursos a partir da percepção de estudantes egressos. Revista Novas Tecnologias na Educação, Porto Alegre, v. 13, n. 1, jul. 2015. Disponível em: https://seer.ufrgs.br/renote/article/view/57667. Acesso em: 20 nov. 2017.

COELHO, M. S. C.; OLIVEIRA, N. C. M. Os egressos no processo de avaliação. Revista ecurriculum, São Paulo, v. 8, n. 2, ago. 2012.

CREA- Conselho Regional de Engenharia e Arquitetura. Salário mínimo profissional.

Disponível em: https://novoportal.crea-rj.org.br/salario-\%20minimo-profissional/. Acesso em: 20 nov. 2017.

DIAS SOBRINHO, J. Avaliação e transformações da educação superior brasileira (19952009): do provão ao SINAES. Avaliação, Campinas; Sorocaba, v. 15, n. 1, p. 195-224, 2010. Disponível em: https://www.scielo.br/pdf/aval/v15n1/v15n1a11.pdf. Acesso em: 20 nov. 2017.

ESPARTEL, L. B. O uso da opinião dos egressos como ferramenta de avaliação de cursos: o caso de uma instituição de ensino superior catarinense. Revista Alcance, Itajaí, v. 16, n. 1, 2009.

FERREIRA, A.; CRISÓSTOMO, J. A influência do desempenho acadêmico na carreira profissional: um estudo de caso em um curso de engenharia. Revista de Ensino em Engenharia, Brasília, v. 30, n. 1, p. 35-44, 2012.

FRAGA, L. O curso de graduação da faculdade de Engenharia de Alimentos da Unicamp: uma analise a partir da educação em ciência, tecnologia e sociedade. 2006. Dissertação (Mestrado em Política Científica e Tecnológica) - UNICAMP, Campinas, 2006.

FRANCISCO, A. M. et al. Avaliação da formação de enfermeiros: o reflexo dos métodos de ensino-aprendizagem e pressupostos curriculares na prática profissional. Avaliação Campinas; Sorocaba, v. 21, n. 2, 2016. Disponível em: https://www.scielo.br/pdf/aval/v21n2/1982-5765-aval-21-02-00479.pdf. Acesso em: 30 mar. 2018. 
GIL, A. C. Como elaborar projetos de pesquisa. São Paulo: Atlas, 2002.

IBGE - Instituto Brasileiro de Geografia e Estatística. Estatística do registro civil em 2015. 2015. Disponível em:

https://biblioteca.ibge.gov.br/visualizacao/periodicos/135/rc_2015_v42.pdf. Acesso em: 20 nov. 2017.

IBGE - Instituto Brasileiro de Geografia e Estatística. Pnad contínua: taxa de desocupação. 2017. Disponível em: https://agenciadenoticias.ibge.gov.br/agencia-sala-de-imprensa/2013agencia-de-noticias/releases/15693-pnad-continua-taxa-de-desocupacao-cai-em-11-das-27-ufsno-2-trimestre-de-2017. Acesso em: 20 nov. 2017.

IGLESIAS, A. G. Perfil dos alunos egressos do curso de Medicina da Faculdade de Medicina de Ribeirão Preto da Universidade de São Paulo. 2016. Tese (Doutorado em Ciências Médicas) - USP, Ribeirão Preto, 2016.

INEP - Instituto Nacional de Pesquisas Educacionais Anísio Teixeira. Sinopse estatística da Educação Superior. Brasília: Inep, 2017.

LIMA; L. A; ANDRIOLA, W. Acompanhamento de egressos: subsídios para a avaliação de Instituições de Ensino Superior (IES). Avaliação, Campinas; Sorocaba, v. 23, n. 1, 2018. Disponível em: https://www.scielo.br/scielo.php?pid=S141440772018000100104\&script=sci_abstract\&tlng=pt. Acesso em: 30 mar. 2018.

LOUSADA, A. C; MARTINS, G. A. Egressos como fonte de informação a gestão dos cursos de Ciências Contábeis. Revista Contabilidade \& Finanças, São Paulo, v. 1, n. 37, 2005.

MACHADO, A. S. Acompanhamento de egressos: caso CEFET/PR - Unidade Curitiba. 2001. Dissertação (Mestrado em Engenharia da Produção) - Universidade Federal de Santa Catarina, UFSC, Florianópolis, SC, 2001.

MACHADO, G. R. Perfil do egresso da Universidade Federal do Rio Grande do Sul. 2010. 337f. Tese. (Doutorado em Educação) - Faculdade de Educação, Universidade Federal do Rio Grande do Sul, Porto Alegre, 2010.

MEIRA, M. D.; KURCGANT, P. Avaliação de curso de graduação segundo egressos. Revista da Escola de Enfermagem da USP, São Paulo, v. 43, n. 2, 2009.

MELO FILHO, D. T. Os egressos do PPGCI/UFPB: representações, perfil e trajetórias profissionais. 2014. Dissertação (Mestrado em Ciências da Informação) UFPB, João Pessoa, 2014.

MICHELAN, L. S. et al. Gestão de egressos em instituições de ensino superior: possibilidades e potencialidades. In: COLÓQUIO INTERNACIONAL SOBRE GESTÃO UNIVERSITÁRIA NA AMÉRICA DO SUL, 9., 2009, Florianópolis. Anais [...]. Florianópolis, 2009.

OLIVEIRA, A. P. et al. Políticas de avaliação e regulação da educação superior brasileira: percepções de coordenadores de licenciaturas no Distrito Federal. Avaliação, Campinas; Sorocaba, v. 18, n. 3, 2013. Disponível em: 
https://www.scielo.br/scielo.php?script=sci_arttext\&pid=S1414-40772013000300007. Acesso em: 30 mar. 2018.

PAUL, J. J. Acompanhamento de egresso do ensino superior: experiência brasileira e internacional. Caderno CRH, Salvador, v. 28, n. 74, p. 309-326, maio/ago. 2015.

PEREIRA, G, M. et al. Panorama de oportunidades para os egressos do ensino superior no Brasil: O papel da inovação na criação de novos mercados de trabalho. Ensaio: avaliação de políticas públicas educacionais, Rio de Janeiro, v. 34, n. 90, 2016.

POLIDORI, M. M. Política de avaliação da educação superior brasileira: provão, SINAES, IDD, CPC, IGC e... outros índices. Avaliação, Campinas; Sorocaba, v. 14, n. 2, 2009. Disponível em: https://www.scielo.br/pdf/aval/v14n2/a09v14n2.pdf. Acesso em: 23 mar. 2018.

QUEIROZ, T. P. O bom filho a casa sempre torna: análise do relacionamento entre a Universidade Federal de Minas Gerais e seus egressos por meio da informação. 2014. Dissertação (Mestrado em Ciência da Informação) - UFMG, Belo Horizonte, 2014.

RAMOS, R. Programa de acompanhamento de estudante egresso da Universidade

Federal do Espírito Santo: diagnóstico e proposta de melhorias em seus instrumentos. 2016. Dissertação (Mestrado Profissional em Gestão Pública) - UFES, Vitória, 2016.

REGIO, M. L. et al. Gestão de competências profissionais na formação de administradores. Avaliação, Campinas; Sorocaba, v. 19, n. 1, 2014. Disponível em:

https://www.scielo.br/pdf/aval/v19n1/07.pdf. Acesso em: 23 mar. 2018.

ROESCH, Sylvia Maria Azevedo. Projetos de estágio e de pesquisa em administração. São Paulo: Atlas, 1999.

SALLES, P. E. A autoavaliação: processo a serviço da gestão. In: COLOMBO, S. Gestão universitária: os caminhos para a excelência. Porto Alegre: Penso, 2013. p. 59-89.

SANTOS, L. et al. Perfil profissional dos egressos do curso de Engenharia Florestal da Universidade Federal de Sergipe (UFS). Scientia Plena, Sergipe, v. 11, n. 1, p. 1-9, 2015.

SCAGLIONE, V. A avaliação da educação superior e a gestão universitária. In: COLOMBO, S. Gestão universitária: os caminhos para a excelência. Porto Alegre: Penso, 2013. p. 43-57.

\section{SCHWARTZMAN, S.; CASTRO, M. H. M. A trajetória acadêmica profissional dos alunos da USP. NUPES: São Paulo, 1991.}

SILVA, J. F. C. Os egressos da Unesp no mercado de trabalho da engenharia cartográfica. In: UNESP. Impacto das novas tecnologias na engenharia cartográfica. Presidente Prudente: Ed. UNESP, 1997. p. 120-126.

SIMON, L. W; PACHECO. A. Ações de acompanhamento de egresso: um estudo das universidades públicas do sul do Brasil. Revista Brasileira de Ensino Superior, Passo Fundo, v. 3, n. 2, 2017. 
SOUTO, R, M. Egressos da licenciatura em matemática abandonam o magistério: reflexões sobre profissão e condição docente. Educação e Pesquisa, São Paulo, v. 42, n. 4, 2016.

TEIXEIRA, D. et al. Perfil e destino ocupacional de egressos graduados em Ciências Biológicas nas modalidades a distância e presencial. Revista Ensaio, Belo Horizonte, v. 16, n. 1, 2014. Disponível em: https://www.scielo.br/pdf/epec/v16n1/1983-2117-epec-16-0100067.pdf. Acesso em: 23 mar. 2018.

VASCONCELOS, N. Egressos na avaliação da qualidade de um curso: o caso da engenharia de produção da UFRN. 2012. Dissertação (Mestrado em Engenharia de Produção)

- Universidade Federal do Rio Grande do Norte, Natal, 2012.

ZAHARIM, A. et al. Engineering employability skill required by employers in Asia. In: WSEAS INTERNATIONAL CONFERENCE ON ENGINEERING EDUCATION, 6., 2009. Stevens Point. Proceedings [...]. Stevens Point, 2009. 